\title{
Design, synthesis, and evaluation of transition-state analogs as inhibitors of the bacterial quorum sensing autoinducer synthase Cepl
}

\author{
Erin L. Higgins ${ }^{\ddagger}$, Julian S. Kellner-Rogers ${ }^{\ddagger}$, Alexandra M. Estanislau, Alec C. Esposito, Nora R. Vail, \\ Sterling R. Payne, Julia G. Stockwell, and Scott M. Ulrich* \\ Department of Chemistry and Biochemistry, Ithaca College, Ithaca NY USA
}

\begin{abstract}
Quorum sensing is a bacterial signaling system that involves the synthesis and subsequent detection of signal molecules called autoinducers. The main autoinducer in Gramnegative bacteria are acylated homoserine lactones, produced by the Luxl family of autoinducer synthase enzymes and detected by the LuxR family of autoinducer receptors. Quorum sensing allows for changes in gene expression and bacterial behaviors in a coordinated, cell density dependent manner. Quorum sensing controls the expression of virulence factors in some human pathogens, making quorum sensing an antibacterial drug target. Here we describe the design and synthesis of transition-state analogs of the autoinducer synthase enzymatic reaction and the evaluation of these compounds as inhibitors of the synthase Cepl. One such compound potently inhibits Cepl and constitutes a new type of inhibitor against this underdeveloped antibacterial target.
\end{abstract}

fThese authors contributed equally to this work.

*Corresponding author: sulrich@ithaca.edu

Current addresses:

ELH: Department of Biochemistry and Molecular Biophysics, University of Chicago, Chicago IL.

JSK-R: Department of Chemistry and Chemical Biology, Cornell University, Ithaca NY.

AME: School of Dental Medicine, University of Connecticut, Farmington CT.

NRV: Department of Chemistry, University of Minnesota, Minneapolis MN.

SRP: Jecho Laboratories, Frederick MD. 


\section{Introduction}

Quorum sensing is a bacterial signaling system that functions through the production, secretion, and detection of small signal molecules called autoinducers ( $\mathrm{Al}){ }^{1-3}$ As bacterial cell population increases, the concentration of autoinducer rises and engages its cognate receptor. The autoinducer-receptor complex acts as a transcriptional regulator allowing for coordinated changes in gene expression at high cell density. The main class of autoinducers in proteobacteria are acylated homoserine lactones (AHLs). The acyl group of AHL structures varies according to species, with lengths between 4 and 18 carbons and variable oxidation states at the beta position. ${ }^{4}$ AHLs are produced by the Luxl family of AHL synthases and are detected by the LuxR family of AHL receptors, named after the Al synthase/receptor pair of the marine bacterium Vibrio fischeri, whose lux bioluminescence operon is controlled by quorum sensing (Figure 1). ${ }^{5}$

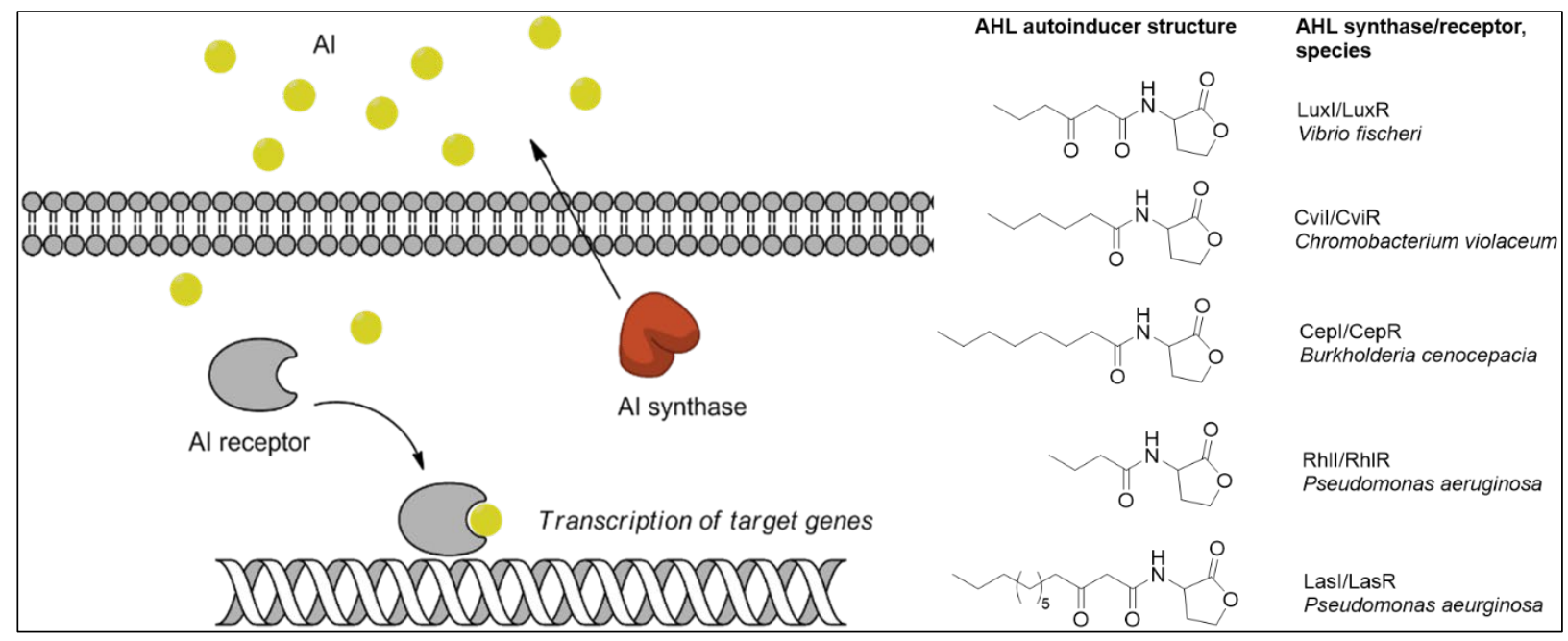

Figure 1. Left: Autoinducer synthases produce Al signal molecules which accumulate in the environment at levels proportional to bacterial cell density. At a threshold concentration, the autoinducers bind their receptors which induces DNA binding and transcription of genes controlled by quorum sensing. Right: Structures of AHL autoinducers from various bacterial species.

Quorum sensing has been shown to control expression of virulence factors in bacteria that are human pathogens. ${ }^{6} \mathrm{~A}$ well-studied example is Pseudomonas aeruginosa, a cause of acute and persistent infections in burn victims, cystic fibrosis patients, and a prominent hospital-acquired infection. ${ }^{7}$ Pseudomonas aeruginosa has two AHL synthase/receptor quorum sensing systems, Lasl/LasR and Rhll/RhIR, which control expression of its pathogenic phenotypes. ${ }^{8}$ These include biofilm formation, antibiotic resistance, motility, and production of the rhamnolipid surfactant, which correlates with disease progression in cystic fibrosis patients. $^{9}$ 
Small-molecule inhibition of quorum sensing is an active area of medicinal chemistry research to suppress the expression of bacterial behaviors that are under quorum sensing control. ${ }^{10,11}$ Numerous potent $\mathrm{AHL}$ receptor antagonists have been developed and evaluated using increasingly sophisticated quorum sensing assays. ${ }^{12,13}$ Some receptor antagonists have been shown to suppress virulence and improve host outcomes in infection models, validating quorum sensing as an antibacterial drug target. ${ }^{14-17}$

An alternative approach to block AHL quorum sensing is to inhibit the AHL synthase enzyme, making bacteria unable to produce signal. Synthases catalyze acyl group transfer from acylated acyl carrier protein (acyl-ACP) to the amino group of S-adenosylmethionine (SAM). The enzyme subsequently catalyzes an intramolecular $S_{N} 2$ lactonization, releasing $S$-methyl thioadenosine (MTA) and the AHL autoinducer (Figure 2). ${ }^{18,19}$

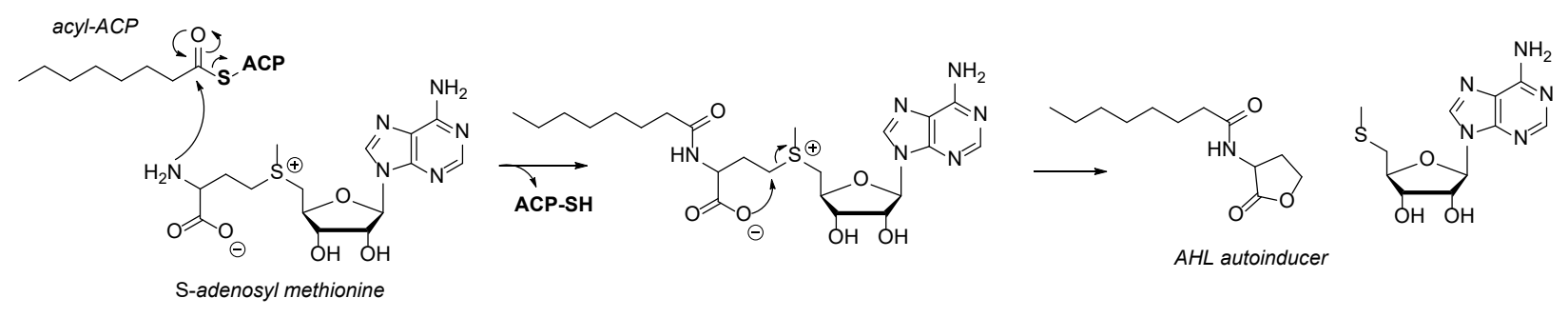

Figure 2. The enzymatic reaction of AHL synthases.

In contrast to the extensive work on AHL receptor antagonists, few AHL synthase inhibitors have been discovered. These can be divided into three classes. First, several inhibitors are autoinducer analogs. These include J8-C8, an acyl-aminocyclohexenone AHL analog, which was co-crystallized with its target Tofl along with MTA, the second AHL synthase product. ${ }^{20} \mathrm{AHL}$ analogs with unnatural $(R)$ stereochemistry and long acyl tails have been shown to inhibit the AHL synthase RhII. ${ }^{21}$ It was proposed that these $(R)$ AHL analogs bind a cryptic pocket on the synthase. Second, bisubstrate analogs with adenosyl and acyl tail moieties joined by linker groups have been shown to be inhibitors of the synthase Tofl. ${ }^{22}$ These molecules were also attached to beads and used as affinity reagents for AHL synthase enzymes. Finally, some AHL synthase inhibitors bear no structural resemblance to any molecule along the reaction coordinate. These include $\mathrm{N}$-hydroxyindole derivatives as inhibitors of AHL synthases Bmal1 and Yspl discovered in a novel high-throughput screening assay ${ }^{23}$, and substituted diketopiperazines as inhibitors of the AHL synthase Cepl. ${ }^{24}$ 


\section{Results and Discussion}

Our approach to develop inhibitors of AHL synthase enzymes was to design transition state analogs of the lactonization step of the enzymatic reaction. The theory of tight binding between enzymes and transition state analogs is well-established and has guided the design of many inhibitors. ${ }^{25,26}$ The lactonization step of this reaction is particularly amenable to the design of transition state mimics. It is a 5-exo-tet cyclization, with the carboxylate displacing the sulfonium group. We designed transition state analogs to capture the cyclic nature of the closing lactone ring, the lengthening of the C-S bond as MTA departs, and the neutralization of the carboxylate and sulfonium charges (Figure 3).

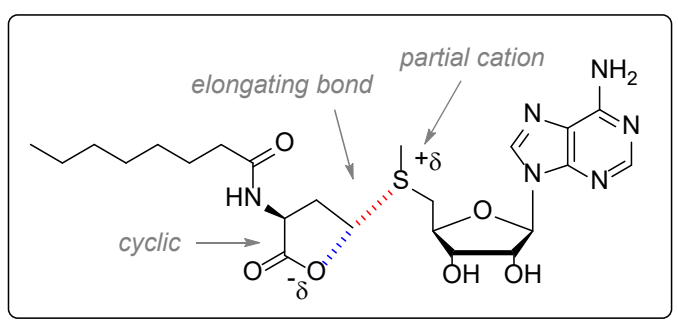

Figure 3. Lactonization transition state of $\mathrm{AHL}$ synthases.

We designed a set of lactonization transition state analogs with lactone, cyclopentyl, and thiazole rings to mimic the nascent lactone of the enzymatic reaction and provide diversity in ring geometry. The rings were joined to adenosine by thioether or amide linkages to mimic the lengthening bond between the lactone ring and departing MTA. The two linker types allow some diversity of the polarity and degree of conformational freedom of this linker. The lactone, cyclopentyl, and thiazole rings all contain an exocyclic amine acylated with an octanoyl group, matching the acyl tail that our target enzyme Cepl incorporates into its AHL product. We also made the corresponding acyclic amide and thioether as control compounds (Figure 4). 

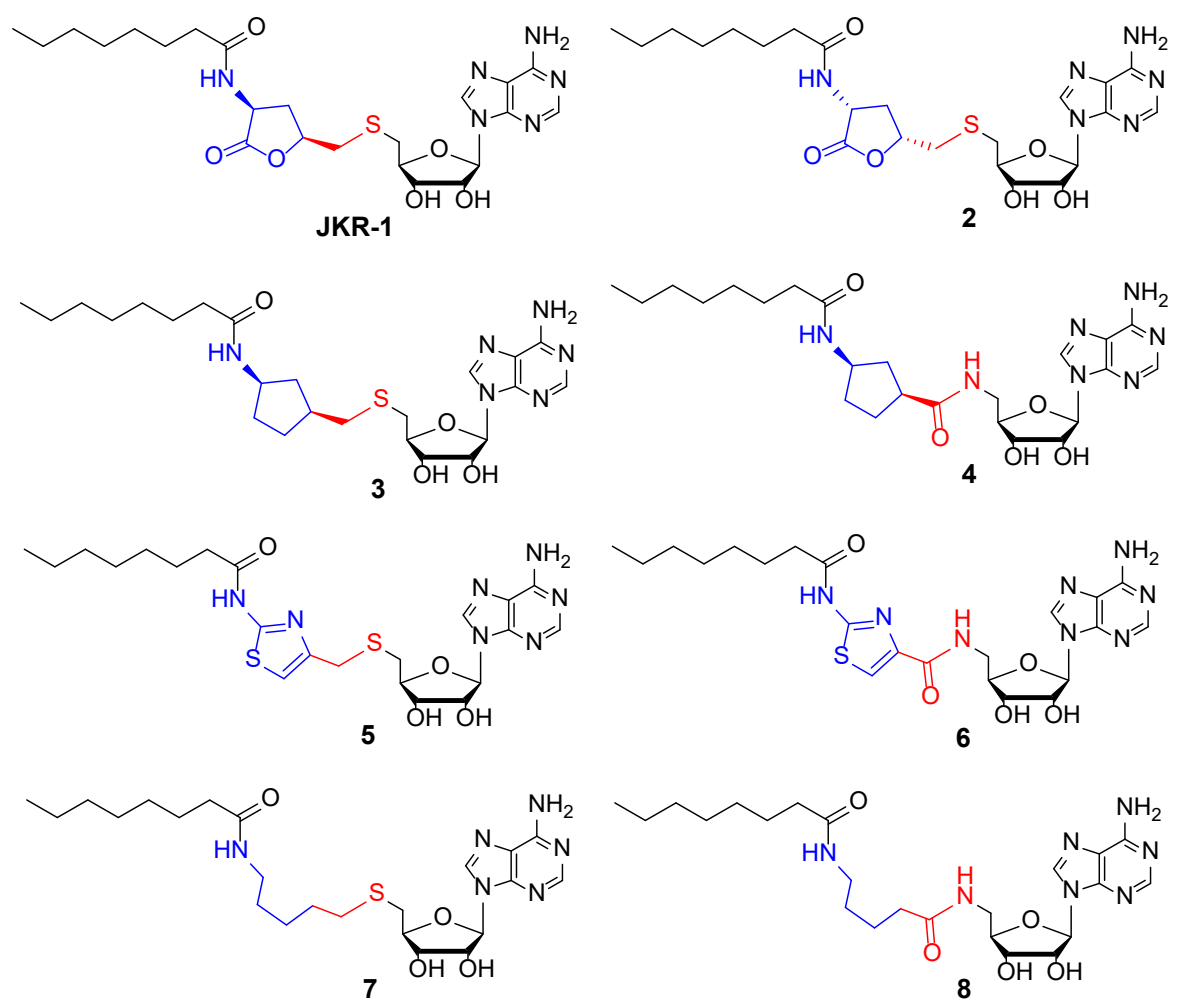

Figure 4. Analogs of the lactonization transition state as target structures for AHL synthase inhibitors.

The thioether compounds JKR-1, 2, 3, 5 and $\mathbf{7}$ were all prepared from 5' thioacetyladenosine acetal, prepared by Mitsunobu reaction of protected adenosine and thioacetic acid. ${ }^{27}$ The $5^{\prime}$ thiol was liberated by basic methanolysis and coupled to suitable halides (Scheme 1).

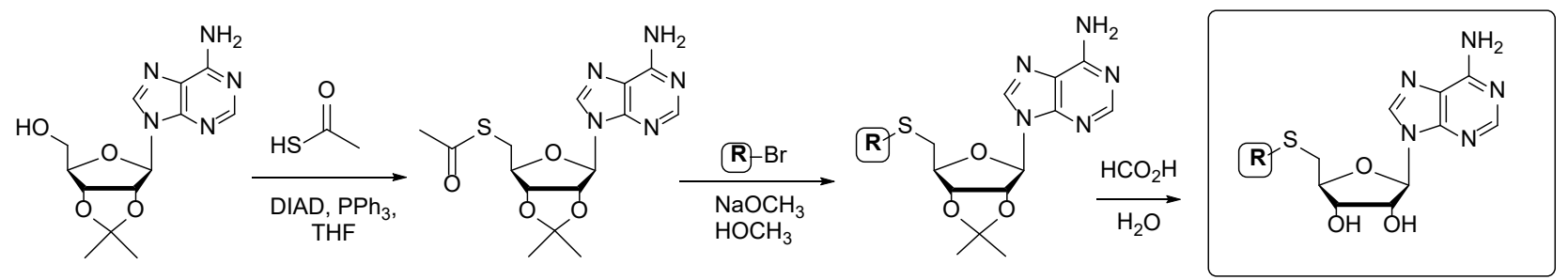

Scheme 1. General synthesis of thioether analogs by coupling alkyl halides with $5^{\prime}$ thioacetyl adenosine acetal. 
The bromides leading to JKR-1 and compound $\mathbf{2}$ were prepared from $(S)$ or $(R)$ Bocallylglycine ${ }^{28}$ which undergoes diastereoselective bromolactonization with NBS. ${ }^{29}$ The Bocbromolactone was deprotected, acylated with octanoyl chloride then coupled to thioadenosine. The synthesis of cyclopentyl analog 3 began with commercially available (1S,3R)-Boc-3aminocyclopentane carboxylic acid which was similarly deprotected and acylated with octanoyl chloride. The acid was esterified and subsequently reduced with methanolic $\mathrm{LiBH}_{4}{ }^{30}$ and brominated under Appel conditions before coupling to thioadenosine. The synthesis of thiazole analog 5 began with acylation of thiourea, ${ }^{31}$ cyclization with 1,3 dichloroacetone ${ }^{32}$ followed by coupling with thioadenosine. The linear analog $\mathbf{7}$ is a known compound and was prepared by the published sequence (Scheme 2). ${ }^{22}$

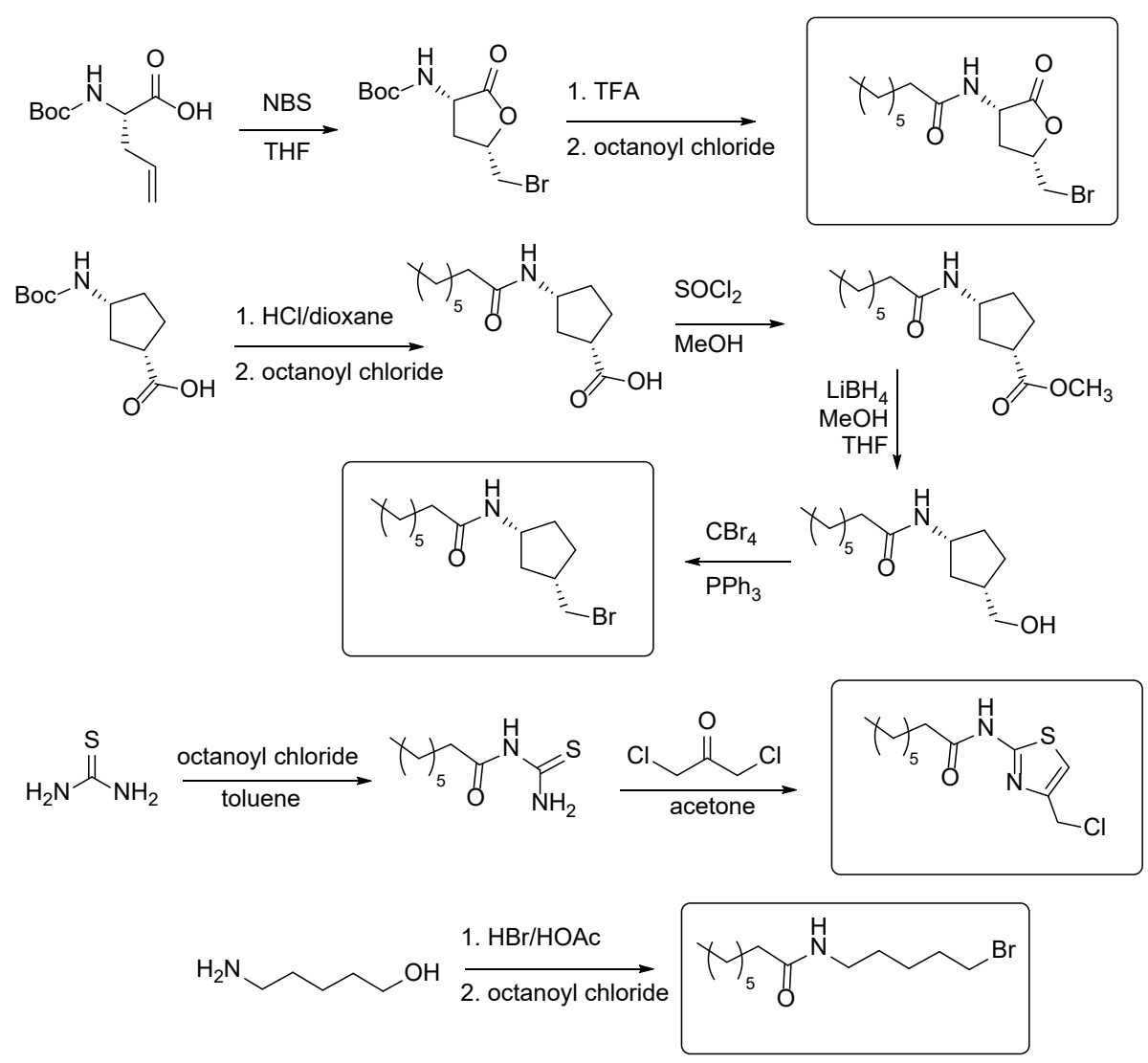

Scheme 2. Synthesis of halides for the lactone JKR-1, lactone 2, cyclopentyl 3, thiazole 5, and acyclic thioether $\mathbf{7}$ transition-state mimics.

The amide-linked analogs 4, 6 and 8 were all prepared by EDC coupling of appropriate carboxylic acids with $5^{\prime}$ aminoadenosine acetonide (Scheme 3 ). ${ }^{33}$ 


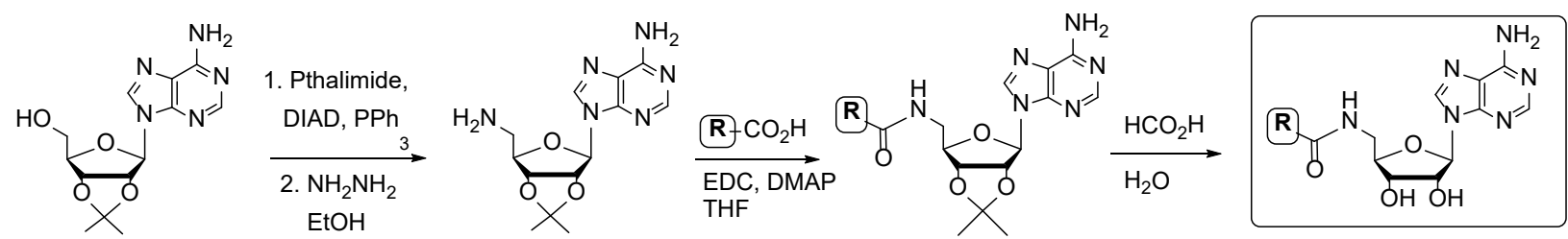

Scheme 3. General synthesis of amide-linked analogs by coupling carboxylic acids with $5^{\prime}$ aminoadenosine acetonide.

The carboxylic acid of the thiazole analog 4 was prepared by acylation of ethyl aminothiazole carboxylate with octanoyl chloride followed by ester hydrolysis. The synthesis of cyclopentyl analog 6 was prepared from the carboxylic acid shown in Scheme 2. The linear amide-linked analog $\mathbf{8}$ was prepared from bromovaleric acid by treatment with sodium azide, reduction to the amine and subsequent acylation with octanoyl chloride (Scheme 4).

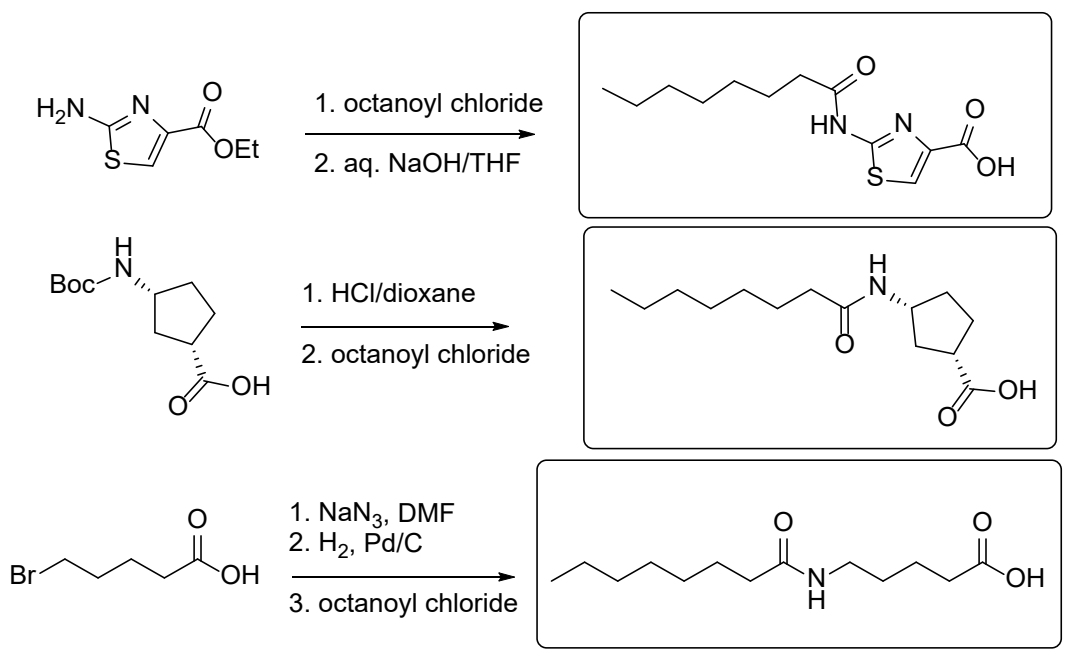

Scheme 4. Synthesis of carboxylic acids for thiazole, cyclopentyl, and linear amide transition-state mimics.

We tested these transition state mimics as inhibitors of Cepl, the autoinducer synthase from Burkolderia cenocepecia. ${ }^{34}$ We screened all compounds in Figure 4 against Cepl at $100 \mu \mathrm{M}$ using the standard DCPIP assay to detect liberated ACP thiol, with $500 \mu \mathrm{M}$ SAM and $15 \mu \mathrm{M}$ octanoyl ACP. We found that JKR-1 and 2, the two lactone-based structures, showed inhibition of Cepl (Figure 5A). We then titrated both these compounds against Cepl under the same assay conditions and found that JKR-1 has an $\mathrm{IC}_{50}$ of $1.0 \pm 0.3 \mu \mathrm{M}$ and 2 has an $\mathrm{IC}_{50}$ of $\sim 100 \mu \mathrm{M}$ (Figure 5B). 

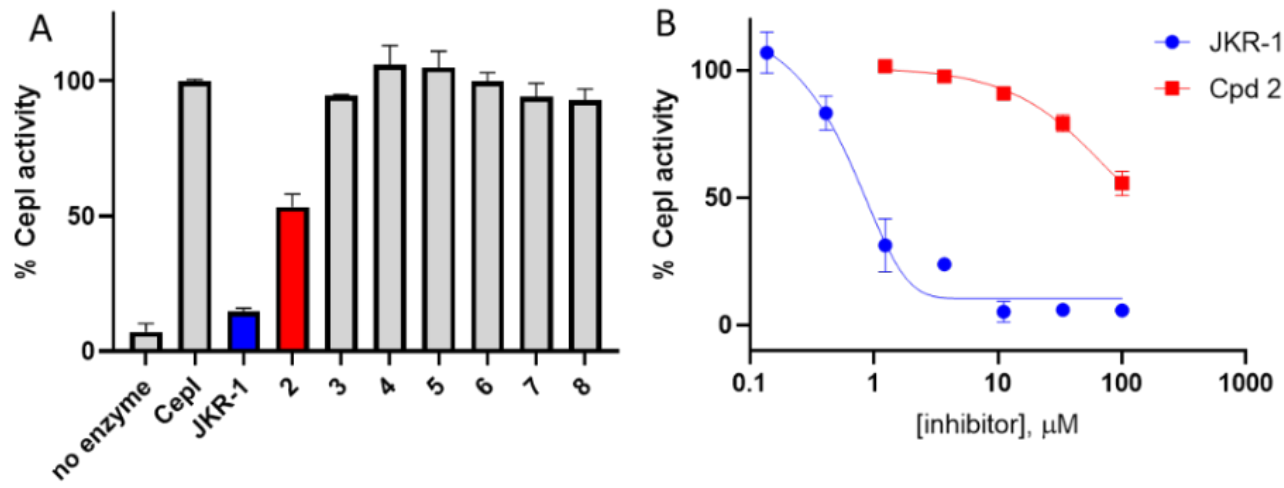

Figure 5. A) Assay of each compound at $100 \mu \mathrm{M}$ for Cepl inhibition. B) Titration of JKR1 and compound 2 against Cepl.

We sought further evidence that JKR-1 binds to Cepl. We observed that addition of JKR$\mathbf{1}$ significantly protected Cepl from proteolysis by trypsin, but not because JKR-1 is a trypsin inhibitor, suggesting that JKR-1 binds Cepl and affects its structure (Figure 6).

A

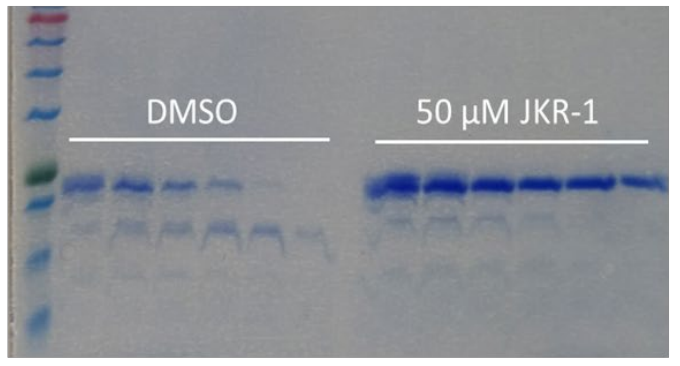

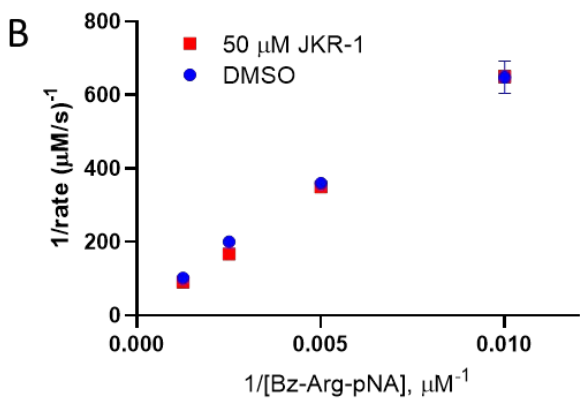

Figure 6. A) Proteolytic digestion of Cepl with Trypsin $(0.1 \mu \mathrm{M})$ for $2.5,5,10,20,40$ and 80 min in the presence or absence of JKR $(50 \mu \mathrm{M})$. B) Trypsin $(1 \mu \mathrm{g} / \mathrm{mL})$ assay with the colorimetric substrate Bz-Arg-pNA in the presence and absence of $50 \mu \mathrm{M}$ JKR-1.

JKR-1 is a new, potent inhibitor of the autoinducer synthase enzyme Cepl. Among the set of molecules described here, JKR-1 is the closest mimic of the "late" lactonization transition state: where the ring is formed, MTA is departing, and the carboxylate and sulfonium charges are neutralized. JKR-1 shares the same $(S)$ stereochemistry at the amino group position as the SAM substrate, which may be why it proved to be a more potent inhibitor than its stereoisomer 2. It is unclear why JKR-1 showed inhibition of Cepl while other closely related molecules (notably compound $\mathbf{3}$ ) did not. The crystal structure of the AHL synthase Tofl bound to the autoinducer analog $\mathrm{J} 8 \mathrm{C} 8$ and reaction byproduct MTA shows that there are distinct binding 
pockets for the SAM and acyl ACP substrates. ${ }^{20}$ These two pockets join at a junction where both the acyl transfer and lactonization chemical steps occur (Figure 7).

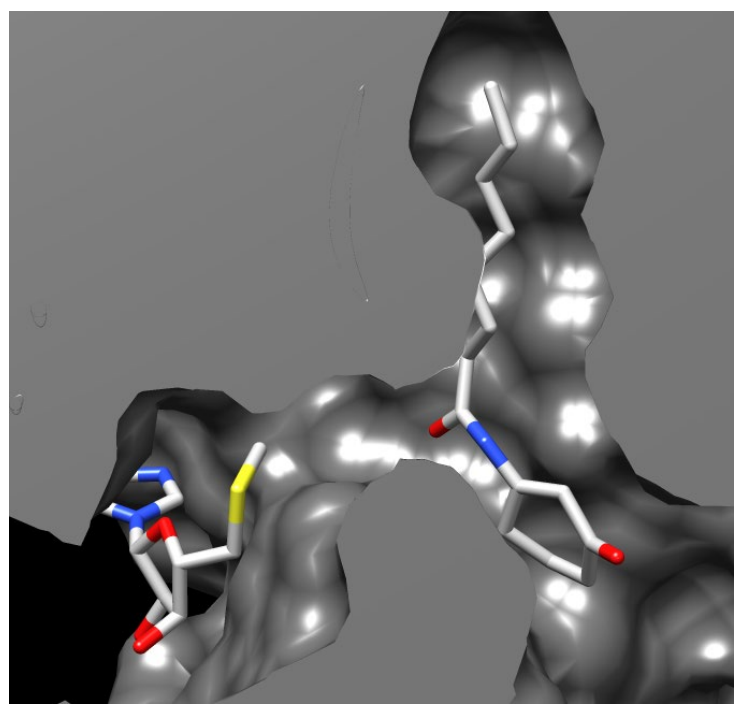

Figure 7. X-ray crystal structure (from reference 20, PDB ID 3P2H) of the synthase Tofl bound to MTA which occupies the adenosyl pocket (left) and the autoinducer analog $\mathrm{J} 8 \mathrm{C} 8$ which occupies the acyl pocket (right).

Our transition state analog JKR-1 contains both adenosyl and acyl groups and therefore likely binds both the adenosyl and acyl tail pockets through this junction. The remainder of the compounds reported here may have failed to inhibit Cepl if there is a strict a geometric requirement to navigate through this junction. JKR-1 may thus provide key initial information on how to effectively do so. This may help lead to potent, cell permeable AHL synthase inhibitors that are useful to block quorum sensing behaviors in bacteria, and ultimately test whether such inhibition is useful to treat bacterial infections.

\section{Acknowledgements:}

This work was supported by NIH grant R15GM131316 awarded to SMU. We thank the Ithaca College Humanities and Sciences Summer Scholars program for funding undergraduate summer internships to E.L.H., N.R.V., J.S.K-R., A.C.E., and J.G.S.

Keywords: Quorum sensing, autoinducer synthase inhibitor, transition-state analog 


\section{References:}

(1) Waters, C. M.; Bassler, B. L. Quorum Sensing: Cell-to-Cell Communication in Bacteria. Annu. Rev. Cell Dev. Biol. 2005, 21, 319-346. https://doi.org/10.1146/annurev.cellbio.21.012704.131001.

(2) Papenfort, K.; Bassler, B. L. Quorum Sensing Signal-Response Systems in Gram-Negative Bacteria. Nat. Rev. Microbiol. 2016, 14 (9), 576-588. https://doi.org/10.1038/nrmicro.2016.89.

(3) Whiteley, M.; Diggle, S. P.; Greenberg, E. P. Progress in and Promise of Bacterial Quorum Sensing Research. Nature 2017, 551 (7680), 313-320. https://doi.org/10.1038/nature24624.

(4) Fuqua, C.; Greenberg, E. P. Self Perception in Bacteria: Quorum Sensing with Acylated Homoserine Lactones. Curr. Opin. Microbiol. 1998, 1 (2), 183-189.

https://doi.org/10.1016/s1369-5274(98)80009-x.

(5) Dunlap, P. V. Quorum Regulation of Luminescence in Vibrio Fischeri. J. Mol. Microbiol. Biotechnol. 1999, 1 (1), 5-12.

(6) Winzer, K.; Williams, P. Quorum Sensing and the Regulation of Virulence Gene Expression in Pathogenic Bacteria. Int. J. Med. Microbiol. IJMM 2001, 291 (2), 131-143. https://doi.org/10.1078/1438-4221-00110.

(7) Sadikot, R. T.; Blackwell, T. S.; Christman, J. W.; Prince, A. S. Pathogen-Host Interactions in Pseudomonas Aeruginosa Pneumonia. Am. J. Respir. Crit. Care Med. 2005, 171 (11), 12091223. https://doi.org/10.1164/rccm.200408-1044SO.

(8) Passador, L.; Cook, J. M.; Gambello, M. J.; Rust, L.; Iglewski, B. H. Expression of Pseudomonas Aeruginosa Virulence Genes Requires Cell-to-Cell Communication. Science 1993, 260 (5111), 1127-1130. https://doi.org/10.1126/science.8493556.

(9) Sawa, T.; Shimizu, M.; Moriyama, K.; Wiener-Kronish, J. P. Association between Pseudomonas Aeruginosa Type III Secretion, Antibiotic Resistance, and Clinical Outcome: A Review. Crit. Care Lond. Engl. 2014, 18 (6), 668. https://doi.org/10.1186/s13054-014-0668-9.

(10) LaSarre, B.; Federle, M. J. Exploiting Quorum Sensing to Confuse Bacterial Pathogens. Microbiol. Mol. Biol. Rev. MMBR 2013, 77 (1), 73-111. https://doi.org/10.1128/MMBR.0004612.

(11) Njoroge, J.; Sperandio, V. Jamming Bacterial Communication: New Approaches for the Treatment of Infectious Diseases. EMBO Mol. Med. 2009, 1 (4), 201-210. https://doi.org/10.1002/emmm.200900032.

(12) Welsh, M. A.; Blackwell, H. E. Chemical Probes of Quorum Sensing: From Compound Development to Biological Discovery. FEMS Microbiol. Rev. 2016, 40 (5), 774-794. https://doi.org/10.1093/femsre/fuw009. 
(13) Geske, G. D.; O’Neill, J. C.; Blackwell, H. E. Expanding Dialogues: From Natural Autoinducers to Non-Natural Analogues That Modulate Quorum Sensing in Gram-Negative Bacteria. Chem. Soc. Rev. 2008, 37 (7), 1432-1447. https://doi.org/10.1039/b703021p.

(14) Swem, L. R.; Swem, D. L.; O’Loughlin, C. T.; Gatmaitan, R.; Zhao, B.; Ulrich, S. M.; Bassler, B. L. A Quorum-Sensing Antagonist Targets Both Membrane-Bound and Cytoplasmic Receptors and Controls Bacterial Pathogenicity. Mol. Cell 2009, 35 (2), 143-153.

https://doi.org/10.1016/j.molcel.2009.05.029.

(15) Welsh, M. A.; Eibergen, N. R.; Moore, J. D.; Blackwell, H. E. Small Molecule Disruption of Quorum Sensing Cross-Regulation in Pseudomonas Aeruginosa Causes Major and Unexpected Alterations to Virulence Phenotypes. J. Am. Chem. Soc. 2015, 137 (4), 1510-1519. https://doi.org/10.1021/ja5110798.

(16) O'Loughlin, C. T.; Miller, L. C.; Siryaporn, A.; Drescher, K.; Semmelhack, M. F.; Bassler, B. L. A Quorum-Sensing Inhibitor Blocks Pseudomonas Aeruginosa Virulence and Biofilm Formation. Proc. Natl. Acad. Sci. U. S. A. 2013, 110 (44), 17981-17986. https://doi.org/10.1073/pnas.1316981110.

(17) Fong, J.; Zhang, C.; Yang, R.; Boo, Z. Z.; Tan, S. K.; Nielsen, T. E.; Givskov, M.; Liu, X.-W.; Bin, W.; Su, H.; Yang, L. Combination Therapy Strategy of Quorum Quenching Enzyme and Quorum Sensing Inhibitor in Suppressing Multiple Quorum Sensing Pathways of P. Aeruginosa. Sci. Rep. 2018, 8 (1), 1155. https://doi.org/10.1038/s41598-018-19504-w.

(18) Raychaudhuri, A.; Jerga, A.; Tipton, P. A. Chemical Mechanism and Substrate Specificity of Rhll, an Acylhomoserine Lactone Synthase from Pseudomonas Aeruginosa. Biochemistry 2005, 44 (8), 2974-2981. https://doi.org/10.1021/bi048005m.

(19) Dong, S.-H.; Frane, N. D.; Christensen, Q. H.; Greenberg, E. P.; Nagarajan, R.; Nair, S. K. Molecular Basis for the Substrate Specificity of Quorum Signal Synthases. Proc. Natl. Acad. Sci. U. S. A. 2017, 114 (34), 9092-9097. https://doi.org/10.1073/pnas.1705400114.

(20) Chung, J.; Goo, E.; Yu, S.; Choi, O.; Lee, J.; Kim, J.; Kim, H.; Igarashi, J.; Suga, H.; Moon, J. S.; Hwang, I.; Rhee, S. Small-Molecule Inhibitor Binding to an N-Acyl-Homoserine Lactone Synthase. Proc. Natl. Acad. Sci. U. S. A. 2011, 108 (29), 12089-12094. https://doi.org/10.1073/pnas.1103165108.

(21) Shin, D.; Gorgulla, C.; Boursier, M. E.; Rexrode, N.; Brown, E. C.; Arthanari, H.; Blackwell, H. E.; Nagarajan, R. N-Acyl Homoserine Lactone Analog Modulators of the Pseudomonas Aeruginosa Rhll Quorum Sensing Signal Synthase. ACS Chem. Biol. 2019, 14 (10), 2305-2314. https://doi.org/10.1021/acschembio.9b00671.

(22) Kai, K.; Fujii, H.; Ikenaka, R.; Akagawa, M.; Hayashi, H. An Acyl-SAM Analog as an Affinity Ligand for Identifying Quorum Sensing Signal Synthases. Chem. Commun. Camb. Engl. 2014, 50 (62), 8586-8589. https://doi.org/10.1039/c4cc03094j. 
(23) Christensen, Q. H.; Grove, T. L.; Booker, S. J.; Greenberg, E. P. A High-Throughput Screen for Quorum-Sensing Inhibitors That Target Acyl-Homoserine Lactone Synthases. Proc. Natl. Acad. Sci. U. S. A. 2013, 110 (34), 13815-13820. https://doi.org/10.1073/pnas.1313098110.

(24) Scoffone, V. C.; Chiarelli, L. R.; Makarov, V.; Brackman, G.; Israyilova, A.; Azzalin, A.; Forneris, F.; Riabova, O.; Savina, S.; Coenye, T.; Riccardi, G.; Buroni, S. Discovery of New Diketopiperazines Inhibiting Burkholderia Cenocepacia Quorum Sensing in Vitro and in Vivo. Sci. Rep. 2016, 6, 32487. https://doi.org/10.1038/srep32487.

(25) Schramm, V. L. Enzymatic Transition States and Drug Design. Chem. Rev. 2018, 118 (22), 11194-11258. https://doi.org/10.1021/acs.chemrev.8b00369.

(26) Schramm, V. L. Transition States, Analogues, and Drug Development. ACS Chem. Biol. 2013, 8 (1), 71-81. https://doi.org/10.1021/cb300631k.

(27) Pignot, M.; Pljevaljcic, G.; Weinhold, E. Efficient Synthesis of S-Adenosyl-L-Homocysteine Natural Product Analogues and Their Use to Elucidate the Structural Determinant for Cofactor Binding of the DNA Methyltransferase M·Hhal. Eur. J. Org. Chem. 2000, 2000 (3), 549-555. https://doi.org/10.1002/(SICI)1099-0690(200002)2000:3<549::AID-EJOC549>3.0.CO;2-7.

(28) ASYMMETRIC SYNTHESIS OF A-AMINO ACIDS BY THE ALKYLATION OF PSEUDOEPHEDRINE GLYCINAMIDE: L-ALLYLGLYCINE AND N-BOC-L-ALLYLGLYCINE. Org. Synth. 1999, 76, 57. https://doi.org/10.15227/orgsyn.076.0057.

(29) Kurokawa, N.; Ohfune, Y. Total Synthesis of Echinocandins. I. Stereocontrolled Syntheses of the Constituent Amino Acids. J. Am. Chem. Soc. 1986, 108 (19), 6041-6043. https://doi.org/10.1021/ja00279a064.

(30) Soai, K.; Ookawa, A. Mixed solvents containing methanol as useful reaction media for unique chemoselective reductions within lithium borohydride https://pubs.acs.org/doi/pdf/10.1021/jo00371a017 (accessed Sep 3, 2020). https://doi.org/10.1021/jo00371a017.

(31) Rutaganira, F. U.; Fowler, M. L.; McPhail, J. A.; Gelman, M. A.; Nguyen, K.; Xiong, A.; Dornan, G. L.; Tavshanjian, B.; Glenn, J. S.; Shokat, K. M.; Burke, J. E. Design and Structural Characterization of Potent and Selective Inhibitors of Phosphatidylinositol 4 Kinase III $\beta$. J. Med. Chem. 2016, 59 (5), 1830-1839. https://doi.org/10.1021/acs.jmedchem.5b01311.

(32) Dayam, R.; Grande, F.; Al-Mawsawi, L. Q.; Neamati, N. Recent Advances in the Design and Discovery of Small-Molecule Therapeutics Targeting HER2/Neu. Expert Opin. Ther. Pat. 2007, 17 (1), 83-102.

(33) Kolb, M.; Danzin, C.; Barth, J.; Claverie, N. Synthesis and Biochemical Properties of Chemically Stable Product Analogs of the Reaction Catalyzed by S-Adenosyl-L-Methionine Decarboxylase. J. Med. Chem. 1982, 25 (5), 550-556. https://doi.org/10.1021/jm00347a014. 
(34) Lewenza, S.; Conway, B.; Greenberg, E. P.; Sokol, P. A. Quorum Sensing in Burkholderia Cepacia: Identification of the LuxRI Homologs CepRI. J. Bacteriol. 1999, 181 (3), 748-756. https://doi.org/10.1128/JB.181.3.748-756.1999. 